\title{
Gastrointestinal Involvement in Systemic Sclerosis
}

\author{
An Update
}

\author{
John B. Miller, MD, * Nisarg Gandhi, MD, † John Clarke, MD, $\ddagger$ and Zsuzsanna McMahan, MD, MHS*
}

S ystemic sclerosis is an autoimmune disease characterized by vasculopathy, progressive fibrosis of the skin, and internal organ dysfunction. Gastrointestinal (GI) disease is the most frequently involved internal organ system in systemic sclerosis and can affect any region across the GI tract. ${ }^{1,2}$ Systemic sclerosis seems to disproportionately affect the upper tract, with evidence of dysmotility in up to $90 \%$ by radionuclide transit time. ${ }^{3}$ The true prevalence of GI involvement is unknown as this may reflect a referral bias, but it is also reported that up to $70 \%$ of patients take medications that specifically address GI symptoms. ${ }^{2}$ However, studies systematically assessing motility from the esophagus through the colon have not been done.

Severity of GI disease has also been shown to be a marker of worse prognosis and mortality in patients with systemic sclerosis. ${ }^{46}$ Gastrointestinal disease can manifest with esophageal dysmotility, gastroparesis, small intestinal bacterial overgrowth, colonic dysmotility, and fecal incontinence. These symptoms have a profound impact on quality of life. ${ }^{5}$ Severity of GI disease has also been shown to correlate with higher depression scores. ${ }^{7}$ This often goes undiagnosed and undertreated as only a fraction of patients report antidepressant use. ${ }^{7}$ Severe GI disease is associated with pseudo-obstruction and malabsorption and may result in dependence on enteral or total parenteral nutrition. ${ }^{8}$ These complications are associated with recurrent hospitalizations, and malabsorption is an independent predictor of mortality. ${ }^{9}$ Given the heterogeneity of symptoms and the complexities related to management, these patients routinely challenge practicing rheumatologists. There is limited information about risk factors associated with severe GI involvement; possible risk factors include presence of anti-U3 RNP, anti-U11/U12 RNP, and anti-muscarinic-3 receptor (M3R) antibodies or African American race. ${ }^{8,10-13}$ In this article, we review the pathophysiology, presentation, diagnostic approach, and treatment strategies for GI dysmotility in systemic sclerosis to relay relevant information to physicians in clinical practice and to clearly define gaps in the field for focus of further research. Other GI manifestations, such as gastric antral vascular ectasia and primary biliary cirrhosis, are beyond the scope of this article.

From the *Division of Rheumatology, Johns Hopkins University School of Medicine, Baltimore, MD; †Presence Medical Center, Des Plaines, IL; and \$Division of Gastroenterology, Stanford University, Palo Alto, CA.

The authors declare no conflict of interest.

Correspondence: John B. Miller, MD, Division of Rheumatology, Johns Hopkins University School of Medicine, 5200 Eastern Ave, Mason F. Lord

Building, Center Tower Suite 4100, Baltimore MD 21224

E-mail: jmill237@jhmi.edu.

Copyright (C) 2017 The Author(s). Published by Wolters Kluwer Health, Inc

This is an open-access article distributed under the terms of the Creative Commons Attribution-Non Commercial-No Derivatives License 4.0 (CCBY-NC-ND), where it is permissible to download and share the work provided it is properly cited. The work cannot be changed in any way or used commercially without permission from the journal.

ISSN: 1076-1608

DOI: 10.1097/RHU.0000000000000626

\section{PATHOPHYSIOLOGY}

Early theories suggested that mechanisms of GI dysmotility in scleroderma may be a consequence of progressive vasculopathy. Autopsy studies assessing esophageal pathology demonstrated concentric intimal thickening of the vasculature with deposition of mucoid substance and collagen fibrils. ${ }^{14}$ There was also evidence of a fibrous cuff around the adventitia, which was frequently found to obliterate periarterial capillaries and lymphatics. This hypothesis was also supported by the correlation between the severity of Raynaud phenomenon and GI involvement. ${ }^{15,16}$

It was later postulated that GI involvement was a consequence of autonomic dysfunction. This was supported by several similarities between esophageal disease and achalasia, a disease of parasympathetic denervation. Importantly, the histology in systemic sclerosis demonstrated differences from achalasia, including the presence of normal numbers of ganglion cells in the plexuses of the esophageal wall along with dilation and thinning of the walls. ${ }^{17}$ Further studies demonstrated that patients with achalasia often have robust improvement in peristalsis with methacholine exposure, but that nearly all patients with systemic sclerosis were resistant to methacholine challenge. ${ }^{18}$ The significant biological differences identified in these studies raised important questions about the underlying mechanisms that distinguish the 2 conditions.

Subsequent studies in patients suggested that GI dysfunction was related to a myopathy or a disease affecting the neuromuscular junction, as there was evidence of smooth muscular atrophy, often preferentially affecting the inner muscularis propria with relative sparing of the longitudinal muscle layer. ${ }^{19-22}$ There was suggestion that this atrophy was related to duration of disease, as it was often not present early. ${ }^{23}$ Studies of the distal GI tract showing that placement of a sacral nerve stimulator alleviated symptoms provided further evidence for the possibility of disease affecting the neuromuscular junction. ${ }^{24}$

Antimyenteric neuronal antibodies were later discovered in a portion of patients with systemic sclerosis who had early presentation of severe GI disease, but were not detected in patients with idiopathic dysmotility. ${ }^{25}$ Passive transfer of these antibodies into mice led to disruption of typical enteric conduction within 7 days with no overt neuronal damage with evidence of concentrationdependent inhibition. ${ }^{26,27}$

This was later characterized as an antibody against the M3R. ${ }^{28}$ Titers of anti-M3R antibodies have a positive correlation with severity of GI symptoms in patients with systemic sclerosis. ${ }^{13}$ Importantly, additional studies demonstrated that pooled human intravenous immunoglobulin may alleviate cholinergic dysfunction associated with GI manifestations, providing further support for anti-M3R antibodies as a potentially important mediator of GI dysmotility in scleroderma. ${ }^{29}$

Although this is an attractive potential mechanism, it likely does not explain the entire spectrum of GI disease in scleroderma. Significant heterogeneity exists among patients, with some patients presenting with a predominance of upper GI dysfunction and others presenting with a predominance of lower GI dysfunction. Whereas the M3R has been shown to be responsible for 
lower esophageal sphincter activity, other receptors, primarily the $\mathrm{M} 2 \mathrm{R}$, are responsible for esophageal motility, suggesting that different biological mechanisms may be important in explaining the phenotypic differences. ${ }^{30-32}$ Systematically defining the specific subsets of GI disease may be important to better understand the pathophysiology.

\section{CLINICAL MANIFESTATIONS}

\section{The Oropharynx}

Systemic sclerosis has numerous deleterious effects on the oropharynx, including reduced oral aperture, salivary hypofunction, increased risk of periodontal disease, difficulty with deglutition, and changes of the mandible. Compared with control subjects, the interincisal distance is reduced on average by $11 \mathrm{~mm}$, approximately $25 \%$ of control subjects. ${ }^{33}$ Reduced oral aperture interferes with mastication and oral hygiene. Exercises that stretch the oral aperture have been shown to alleviate interincisal distance by up to $10 \mathrm{~mm}$, although these benefits are not long-lasting, and studies have shown a reduced benefit after 6 months. ${ }^{34,35}$ Surgical approaches, including perioral fat grafting and carbon dioxide laser therapy, may have a role in refractory disease, although these therapies are experimental at this time. ${ }^{36}$

Salivary dysfunction can be seen in up to half of patients with systemic sclerosis. ${ }^{33,37}$ Approximately a third of patients who underwent labial gland biopsy were found to have periductal and/or interstitial fibrosis without lymphoid aggregates. ${ }^{33}$ Patients with abnormal biopsies were more likely to have positive antiSSA and anti-SSB antibodies. There is also evidence that salivary hypofunction correlates with a greater reduction in interincisal distance. Although this is suggestive of increased fibrotic activity, these findings are independent of the pattern of skin involvement. Importantly, reduced oral aperture, salivary hypofunction, and difficulty with oral hygiene all lead to increased periodontal and carious disease compared with control subjects. ${ }^{38}$ Treatment of sicca syndrome associated with systemic sclerosis remains limited. We recommend supportive therapy, maintaining hydration, and use of artificial salivary products as needed. There is limited evidence regarding the use of sialogogues in systemic sclerosis.

In addition to developing sicca symptoms, approximately $25 \%$ of patients with systemic sclerosis may develop oropharyngeal deglutition dysfunction. ${ }^{39}$ Video fluoroscopy has shown that this is related to tongue-palate incompetence, inadequate pharyngeal contraction, and laryngeal and epiglottic dysfunction. ${ }^{39,40}$ Oropharyngeal dysfunction is related to duration of disease, occurring several years after the onset of Raynaud phenomenon. ${ }^{39}$ This has also been associated with esophageal and pulmonary disease. If there is evidence of oropharyngeal dysfunction on video fluoroscopic swallow study, we recommend that patients work with speech therapists to optimize swallowing mechanics and minimize risk of aspiration.

\section{The Esophagus}

Esophageal involvement in systemic sclerosis is associated with a hypotensive lower esophageal sphincter and/or reduced or absent peristalsis. ${ }^{40}$ Esophageal involvement is highly prevalent in systemic sclerosis, involving approximately $90 \%$ of patients. ${ }^{3,22,40,41}$ This is associated with reflux esophagitis, stricture formation, Barrett esophagus, and adenocarcinoma. ${ }^{42,43}$

Esophageal disease has been shown to correlate with the severity of lung disease. Reflux and regurgitation positively correlate with degree of pulmonary fibrosis, ${ }^{44-47}$ yet there is suggestion that diarrhea and lower GI involvement may negatively correlate with pulmonary fibrosis. ${ }^{2}$ Studies have shown that patients with interstitial lung disease have a high frequency of symptomatic reflux along with increased occurrence of reflux episodes reaching the proximal esophagus, although the causal association has not been determined. ${ }^{44} 47$

Presentation is variable with patients often presenting with symptoms of reflux or dysphagia. However, there is a high prevalence of esophageal disease in asymptomatic patients. When evaluated by endoscopy, up to $80 \%$ of asymptomatic patients have been found to have evidence of reflux esophagitis or dysmotility. ${ }^{41}$ Gastroesophageal reflux disease is often present early in the course of systemic sclerosis, unlike dysmotility disorders.

Evaluation for esophageal disease is directed by the initial clinical presentation. Patients who present with typical symptoms of reflux should be treated empirically, given the high prevalence in systemic sclerosis. However, if empiric therapy fails, patients require evaluation for mechanical obstruction and dysmotility. Barium swallow is often recommended as the next step in evaluation because it is able to detect both processes and is noninvasive, although endoscopy is often pursued, given the potential for simultaneous therapeutic intervention. However, the sensitivity is limited, with barium swallow detecting between $50 \%$ and $70 \%$ of all patients with dysmotility. ${ }^{3,40,48}$ If there is concern for inadequate acid suppression, 24-hour $\mathrm{pH}$ monitoring may potentially be revealing. If there is concern for dysmotility, manometry has shown to have higher sensitivity and is recommended if initial evaluation is unrevealing. If there is concern for a mechanical obstruction, endoscopy is recommended because this is both diagnostic and potentially therapeutic.

Gastroesophageal reflux disease is largely attributed to a hypotensive lower esophageal sphincter and dysmotility. ${ }^{49}$ We recommend lifestyle modifications to all affected patients, including avoidance of alcohol and tobacco, sitting upright for at least 3 hours after meals, and elevation of the head of the bed. ${ }^{50}$ Acid suppression with proton pump inhibitors or $\mathrm{H}_{2}$-receptor antagonists is the preferred initial therapy for symptoms of reflux in patients with scleroderma. ${ }^{51,52} \mathrm{H}_{2}$-receptor antagonists are generally useful for mild symptoms with use of proton pump inhibitors reserved for moderate to severe disease. A study evaluating the use of omeprazole in patients with scleroderma who failed ranitidine showed that use of omeprazole, between 20 and $80 \mathrm{mg}$ daily, resulted in rapid symptomatic improvement, healing esophagitis, and less time with $\mathrm{pH}$ less than 4 during 24-hour ambulatory $\mathrm{pH}$ monitoring. ${ }^{52}$ However, more than half of patients treated with proton pump inhibitors had residual low-grade esophagitis or had recurrent episodes of $\mathrm{pH}$ less than 4 . This has been attributed to parietal cell hypertrophy associated with increased acid secretion. ${ }^{53}$ It is important to discuss the risks associated with prolonged use of proton pump inhibitors, including the association with renal insufficiency, osteoporosis, atypical fractures, pneumonia, and dementia. ${ }^{54-57}$

Nocturnal symptoms are often present in patients with gastroesophageal reflux disease. It is reported that twice-daily dosing of a proton pump inhibitor may alleviate nocturnal symptoms. ${ }^{58,59}$ Histamine receptor blockade in the evening is also associated with reduced nocturnal gastric acid breakthrough in any patient with twice-daily or evening use of a proton pump inhibitor. ${ }^{60}$ However, the efficacy of prolonged use of histamine blockade is limited as studies have shown no difference in nocturnal acid breakthrough after 7 and 28 days. ${ }^{61}$ Previous studies have shown that discontinuation of histamine blockade is associated with early, symptomatic relapse. ${ }^{62}$ Prolonged acid suppression has not been shown to affect motility. ${ }^{51}$

If reflux persists despite acid suppression, it is recommended to pursue diagnostic testing for dysmotility, obstruction, and inadequate acid suppression. Endoscopic dilatation of a stricture is indicated if the patient has dysphagia in addition to reflux. For 
management of dysmotility, we recommend use of prokinetic agents. Metoclopramide has been shown to increase lower esophageal sphincter tone in patients with early disease without significant improvement in motility. ${ }^{63-65}$ In a study of patients with systemic sclerosis with partial response to proton pump inhibitors, addition of domperidone resulted in reduced frequency and severity of symptoms and improved quality of life. ${ }^{66}$ It is worth noting that the addition of antacids had similar results as domperidone. Domperidone is associated with cardiac arrhythmia. ${ }^{67}$ It is not US Food and Drug Administration (FDA) approved but can be obtained in the United States with completion of the Investigational New Drug Application through the FDA. Prucalopride has been shown to increase antroduodenal motility and may be a potential treatment option in the future. ${ }^{68}$ Surgical options, including esophagectomy, fundoplication, and roux-en-Y gastric bypass, have been evaluated for refractory reflux. There was symptomatic improvement in reflux and dysphagia with bypass, although surgical intervention is typically not pursued, given the risk of postoperative complications and exacerbation of nutrient deficiencies. ${ }^{69}$

Buspirone and baclofen have recently been evaluated as agents for persistent gastroesophageal reflux. In patients with systemic sclerosis, buspirone has been shown to acutely increase the lower esophageal sphincter pressure, increase the amplitude of esophageal contractions, and alleviate fundic accommodation. ${ }^{70}$ Use of daily buspirone for 4 weeks has been shown to alleviate symptoms associated with reflux. ${ }^{71}$ Baclofen has been shown to augment lower esophageal sphincter pressure in patients with gastroesophageal reflux disease and decrease reflux numbers, although this has not been studied in patients with systemic sclerosis. ${ }^{72}$

\section{The Stomach}

Gastroparesis presents with early satiety, postprandial nausea, distention, and abdominal pain. ${ }^{73}$ These symptoms can be seen in up to $80 \%$ of patients with systemic sclerosis. ${ }^{1}$ Postprandial nausea and early satiety correlate best with gastroparesis. However, these symptoms are nonspecific and can be seen with gastritis, peptic ulcer disease, functional dyspepsia, Helicobacter pylori infection, and gastric outlet obstruction. ${ }^{73}$

Unlike esophageal disease, evaluation for gastric dysmotility is generally required prior to initiation of therapy. ${ }^{73}$ Scintigraphic gastric emptying of solids is the recommended test for evaluation of motility, with emptying at 4 hours representing the most reliable parameter. This can be done with a focused gastric-emptying study, or if more diffuse bowel involvement is suggested, a whole-gut transit study may be performed. ${ }^{74}$ Combined gastric-emptying studies, including the assessment of both solids and liquids, increase the sensitivity for detection of gastroparesis. ${ }^{75}$ This is important in scleroderma because delayed transit of liquids is commonly reported in this patient population. ${ }^{76}$ Although the mechanism of abnormal emptying of liquids is unclear, studies have suggested that this finding correlates with symptoms of early satiety and anorexia in patients with scleroderma. ${ }^{77}$ Wireless capsule motility testing is another assessment tool to evaluate gastroparesis. It detects transition from stomach to small bowel through changes in $\mathrm{pH}$, pressure, and temperature. This measure is demonstrated to correlate well with the 4-hour gastric-emptying time and offers a nonradioactive alternative for patients who are unable to tolerate the meal for gastric emptying. ${ }^{78}$ Carbon-labeled radioactive breath testing is a cheap and noninvasive alternative that can be used for assessment of gastric dysmotility. ${ }^{79,80}$ Carbon-labeled radioactive breath testing has been shown to correlate well with scintigraphic emptying time. ${ }^{79}$

Lifestyle modification is important for management of gastroparesis. Patients are encouraged to consume small, frequent meals. Review of the medication list is important because several medications, including opiates and neuroleptics, can affect gastric transit time. ${ }^{81,82}$ If lifestyle modifications do not sufficiently control symptoms, prokinetic agents are recommended. Response to therapy is evaluated by symptomatic control rather than repeating functional studies.

The American College of Gastroenterology recommends metoclopramide as the first-line agent for treatment of gastroparesis. ${ }^{73}$ It is a direct $\mathrm{D}_{2}$-receptor antagonist and $5-\mathrm{HT}_{4}$ agonist that has been shown to alleviate nausea and postprandial distention, as well as improve gastric-emptying time. ${ }^{83-85}$ These results are largely extracted from the treatment of gastroparesis in diabetic patients, although there are few small studies showing metoclopramide may increase gastric motility in patients with systemic sclerosis. ${ }^{64,86}$ This should be administered orally 30 to 60 minutes before a meal to facilitate absorption. As metoclopramide crosses the blood-brain barrier, it is also associated with high rates of extrapyramidal symptoms through $\mathrm{D}_{2}$-receptor antagonism. The FDA advised against use for more than 3 months because of the risk of tardive dyskinesia. ${ }^{87-89}$ Metoclopramide has also been shown to prolong the QT interval and has been associated with fatal arrhythmias in patients with systemic sclerosis. ${ }^{90}$ An electrocardiogram should be obtained prior to initiation to evaluate for prolonged QT interval.

Domperidone, a peripheral $\mathrm{D}_{2}$-receptor antagonist, is recommended as a second-line agent. ${ }^{73}$ Domperidone does not cross the blood-brain barrier and is not associated with extrapyramidal symptoms, although the pituitary remains exposed, and patients often experience symptoms of hyperprolactinemia. ${ }^{87}$ Studies have shown that domperidone is as efficacious as metoclopramide in symptomatic improvement, and up to $90 \%$ of patients have improved quality of life. ${ }^{91,92}$ Our center has found domperidone to be very effective for management of refractory gastroparesis. Although there is symptomatic improvement, there is not often objective evidence of improved gastric-emptying times for solid foods. ${ }^{93,94}$

In patients with refractory gastroparesis, stimulation of the motilin receptors with erythromycin has shown benefit. Patients with diabetic gastroparesis demonstrated near resolution of gastricemptying times following administration of intravenous erythromycin, and the improvement in gastric-emptying time was reproduced in patients with systemic sclerosis. ${ }^{95,96}$ As the effect of erythromycin on motility seems to have a greater effect on solids, it may be more beneficial to patients with specific delays in solid gastric emptying. ${ }^{96,97}$ Despite the objective improvement in gastric motility, patients often do not have sustained symptomatic improvement with erythromycin suggestive of tachyphylaxis. ${ }^{98,99}$ Prolonged use is not recommended because there is also evidence that erythromycin may delay small bowel transit. ${ }^{97,100-103}$ Erythromycin is also associated with QT-interval prolongation, and electrocardiogram monitoring is required.

Cisapride, a 5- $\mathrm{HT}_{4}$ agonist and $5-\mathrm{HT}_{3}$ receptor antagonist, has been shown to alleviate postprandial symptoms and gastric transit time in patients with diabetic gastroparesis. ${ }^{104}$ This was previously found to be more potent acutely than metoclopramide in patients with diabetes. ${ }^{105}$ Cisapride also has the benefit of increasing esophageal contractions and lower esophageal sphincter tone and decreasing small bowel transit time, although it was also shown to increase colonic transit time. ${ }^{87,106}$ Cisapride was withdrawn from the market because of several episodes of cardiac arrhythmia, although this risk was largely attributable to baseline long QT interval and use of CYP3A4 inhibitors. ${ }^{107}$ This was thought to be due to the benzamide structure rather than serotonin agonism. ${ }^{87}$ Buspirone, a $5-\mathrm{HT}_{1 \mathrm{~A}}$ receptor partial agonist is also demonstrated to alleviate gastric accommodation and alleviate symptoms in patients with functional dyspepsia, although it has been shown to decrease gastric emptying of liquids. ${ }^{108}$ 
Levosulpiride is another $\mathrm{D}_{2}$-receptor antagonist used to treat gastroparesis that is not available in the United States. It has been shown to decrease gastric-emptying times and alleviate symptoms of gastroparesis. ${ }^{109,110}$ It was shown to be superior to metoclopramide and domperidone in symptomatic improvement in patients with functional dyspepsia, although this has not been shown in patients with systemic sclerosis. ${ }^{111}$ Prucalopride has been shown to alleviate antroduodenal motility and may have a role in gastroparesis. ${ }^{68}$

Ghrelin is a neurohormone secreted from the stomach and small intestine in response to stretch receptors and has been shown to decrease appetite and increase gastric motility. Ghrelin infusion has been shown to alleviate symptoms and gastric emptying in patients with diabetic gastroparesis. ${ }^{112,113}$ Similar results were reproduced in patients with systemic sclerosis, suggesting a potential target for therapy. ${ }^{114}$

Antiemetic therapy is often required for management of gastroparesis. Serotonin antagonists (e.g., ondansetron, granisetron), dopamine antagonists (e.g., metoclopramide, domperidone, prochlorperazine), antihistamines (e.g., promethazine, meclizine), benzodiazepines (e.g., lorazepam), and cannabinoids (e.g., dronabinol) have a role in management of gastroparesis. It is important to be mindful of drug-drug interactions when selecting an antiemetic.

Invasive procedures, including Botox injections and implantation of a gastric stimulator, are believed to have a limited role in systemic sclerosis.

\section{The Small Bowel}

Small bowel dysmotility may be seen in up to $60 \%$ to $80 \%$, depending on disease duration. ${ }^{115,116}$ Studies have shown reduced amplitude and frequency of the migrating motor complex in systemic sclerosis. ${ }^{98,115}$ This results in delayed transit through the small bowel. ${ }^{117}$ Delayed small bowel transit is associated with small intestine bacterial overgrowth (SIBO) and pseudoobstruction. ${ }^{118}$

Small intestine bacterial overgrowth often presents with postprandial distention, nausea, diarrhea, and excessive flatulence. ${ }^{119}$ This is associated with malabsorption leading to deficiencies of vitamin $\mathrm{B}_{12}$, iron, and fat-soluble vitamins. ${ }^{120}$ Approximately $40 \%$ of patients with systemic sclerosis are affected by SIBO. ${ }^{121}$ The criterion standard for diagnosis is endoscopy with aspiration of proximal jejunal contents with growth of more than 100,000 colony-forming units per milliliter. The role of jejunal aspiration, an invasive procedure, has largely been replaced with the hydrogen and methane breath tests. As neither substance is created in humans, the presence of hydrogen and methane tests for fermentation of carbohydrates by intraluminal bacteria. The sensitivity ranges between $50 \%$ and $60 \%$, and specificity between $80 \%$ and $90 \%$, depending on the molecule ingested. ${ }^{122}$ Hydrogen breath tests can be affected by diet, tobacco use, carbohydrate malabsorption, gastroparesis, colonization with non-hydrogen-producing microbes, and medications. ${ }^{123,124}$ For instance, proton pump inhibition has been shown to increase bacterial counts on jejunal aspirates without changing results from breath tests. ${ }^{125}$

As the diagnostic yield from breath tests is limited, most clinicians prefer empiric therapy with broad-spectrum antibiotics. Rifaximin, metronidazole, amoxicillin/clavulanic acid (Augmentin), and norfloxacin have all been shown to alleviate symptoms, as well as breath testing in all patients with SIBO ${ }^{126-128}$ Rifaximin showed greater improvement in breath testing with fewer adverse effects when compared with metronidazole. ${ }^{128}$ Small intestine bacterial overgrowth is typically treated for 2 weeks. If there is subjective improvement, patients can be monitored for recurrence. The risk of recurrent SIBO remains high because of ongoing small bowel dysmotility, and this is typically treated with cyclic antibiotic regimens to limit antimicrobial resistance.

The role of probiotics in management of SIBO is less clear but may have a supportive role. Probiotics have been shown to alleviate symptoms of reflux associated with SIBO. ${ }^{129,130}$ Limited studies in systemic sclerosis have suggested symptomatic improvement in patients treated with probiotics, Align or Culturelle, for 2 months. ${ }^{131}$ The role of promotility agents in treatment of SIBO is limited, although previous studies have shown that treatment with octreotide in patients with scleroderma can reduce hydrogen breath excretion, as well as alleviate nausea, distention, and abdominal pain. ${ }^{132}$

Intestinal pseudo-obstruction presents with abdominal pain, nausea, and abdominal distention. Imaging demonstrates upper intestinal distention in the absence of a mechanical obstruction. Similar to small bowel obstruction, intestinal pseudo-obstruction is often managed conservatively with bowel rest, fluid resuscitation, correction of electrolyte derangements, and empiric antibiotics for management of coexistent SIBO. It is important to discontinue any offending medications.

If there is no improvement with conservative management, prokinetic agents may be helpful. Prokinetic agents typically have a more profound effect early in the course of disease, although as smooth muscle atrophies, their role is less clear. Metoclopramide has been shown to increase motility of the small bowel in patients with scleroderma, although there is not a defined role for its use in pseudo-obstruction. ${ }^{133}$ Cisapride has been shown to alleviate intestinal motility but is not associated with symptomatic improvement. ${ }^{134}$ Intestinal transit time is not significantly affected by erythromycin. ${ }^{103}$ Initial studies have suggested symptomatic relief in patients with recurrent pseudo-obstruction treated with pyridostigmine. ${ }^{135}$

Octreotide, a somatostatin analog, has a role in management of chronic pseudo-obstruction. It has been shown to initiate small bowel migrating motor complexes. ${ }^{114,132}$ In patients with systemic sclerosis who failed to respond to other prokinetic agents, octreotide was well tolerated and alleviated symptoms. ${ }^{136}$ However, octreotide has been shown to inhibit gastric contractions in patients with systemic sclerosis. ${ }^{132}$ In a study of chronic pseudoobstruction, patients receiving octreotide in addition to erythromycin, to account for inhibition of gastric contractions, had symptomatic improvement and weight gain. ${ }^{98}$

Surgical intervention for pseudo-obstruction is avoided if possible. Pneumatosis cystoides intestinalis is a condition associated with pseudo-obstruction and SIBO and can generally be treated conservatively ${ }^{137}$ However, patients require close monitoring for bowel perforation. ${ }^{138}$ Rarely, intervention is needed for decompression, although this is uncommon for small bowel dysmotility.

\section{The Colon}

Colonic involvement in systemic sclerosis presents with diarrhea, constipation, and fecal incontinence. These symptoms have a prominent effect on quality of life, and patients often report avoiding travel and social events because of these symptoms. ${ }^{139}$ Constipation is often prominent early in the course and is associated with colonic dysmotility. Diarrhea often occurs with prolonged disease and is multifactorial, due to coexistent SIBO, fibrosis of lymphatic drainage, impaired reabsorption, and medications for upper GI disease. Steatorrhea and malabsorption may be markers of overlap primary biliary cirrhosis. Workup for these symptoms is often limited and directed by history, but if symptoms are refractory to standard therapy, objective testing may be pursued (e.g., sitz markers, whole-gut transit). ${ }^{74}$ Sitz markers and capsule endoscopy do carry an associated risk of retention in this population with potentially severe dysmotility. ${ }^{140}$ 
TABLE. Gastrointestinal Manifestations of Systemic Sclerosis

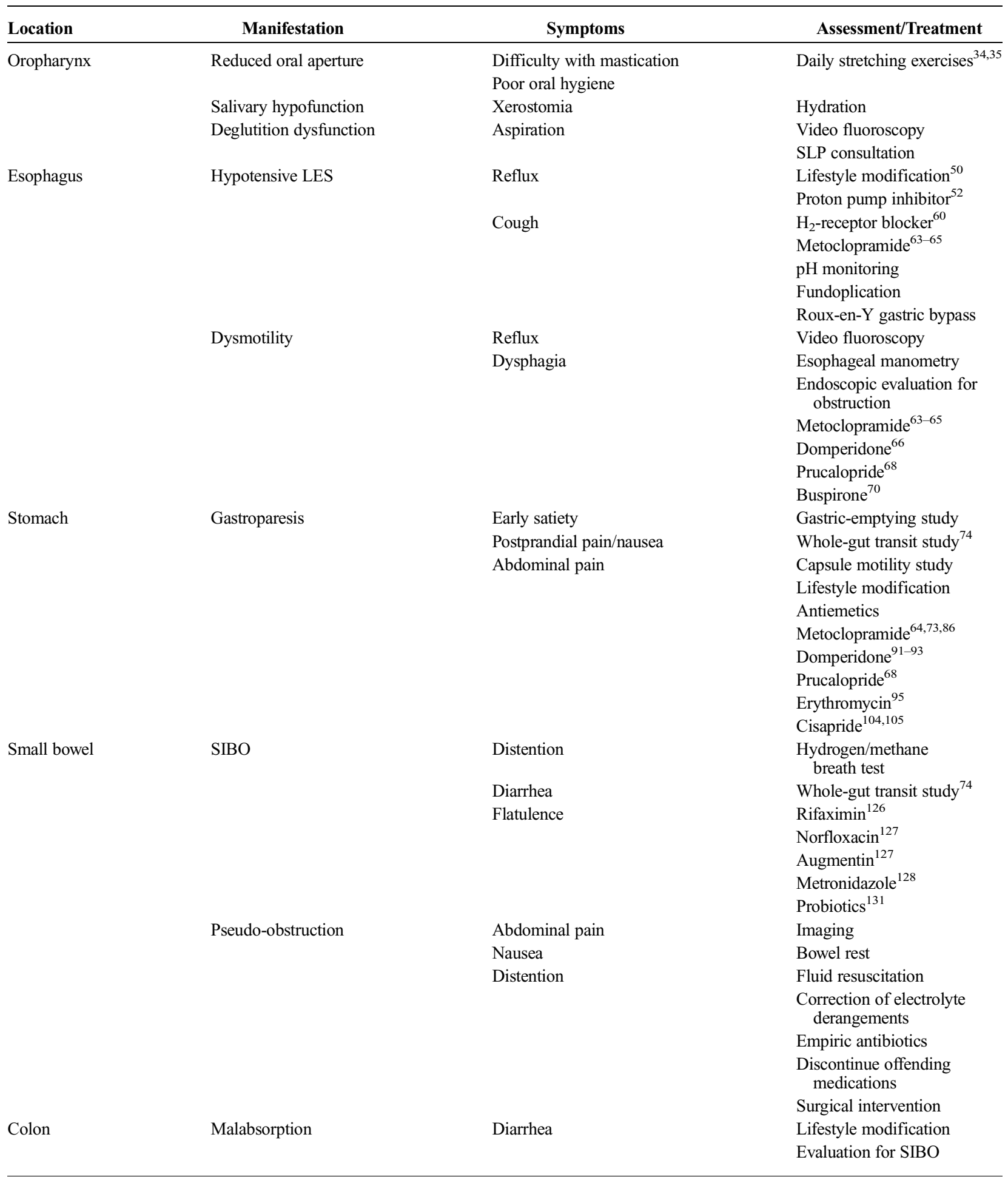


TABLE. (Continued)

\begin{tabular}{|c|c|c|}
\hline \multirow[t]{11}{*}{ Dysmotility } & Constipation & Whole-gut transit study ${ }^{74}$ \\
\hline & & Sitz markers \\
\hline & & Capsule motility study \\
\hline & & Lifestyle modification \\
\hline & & Osmotic laxatives ${ }^{141}$ \\
\hline & & Stimulant laxatives \\
\hline & & Linaclotide $^{143}$ \\
\hline & & Lubiprostone $^{142}$ \\
\hline & & Pyridostigmine $^{135}$ \\
\hline & & Prucalopride $^{68}$ \\
\hline & & Surgical intervention ${ }^{144}$ \\
\hline \multirow[t]{5}{*}{ Hypotensive sphincter } & Fecal incontinence & Lifestyle modification \\
\hline & & Pelvic physical therapy ${ }^{150}$ \\
\hline & & Injectable bulking agent ${ }^{151}$ \\
\hline & & $\begin{array}{l}\text { Antidiarrheal medications } \\
\text { (loperamide) }\end{array}$ \\
\hline & & Sacral nerve stimulator ${ }^{152}$ \\
\hline
\end{tabular}

LES indicates lower esophageal sphincter; SLP, speech-language pathology.

Lifestyle modification is important for management of constipation. Patients are encouraged to keep hydrated. Several medications can cause constipation, so it is important to evaluate the patient's medication list. We recommend evaluation of electrolyte derangements as constipation may be associated with malnutrition.

If conservative management fails, we recommend initial treatment with fiber-based, bulk-forming laxatives (e.g., psyllium, methylcellulose). Patients with upper GI involvement may find this difficult to tolerate. Osmotic laxatives (e.g., polyethylene glycol) have been shown to increase bowel movements and relieve symptoms in patients with constipation-predominant irritable bowel syndrome (IBS-C), although there was no significant difference compared with placebo. ${ }^{141}$ Stimulant laxatives (e.g., bisacodyl, glycerol) are often used for IBS-C. Linaclotide, a selective agonist of the guanylate cyclase- $\mathrm{C}$ receptor, and lubiprostone, a fatty acid that activates chloride channels in the GI tract, have been shown to be efficacious in patients with refractory IBS-C. ${ }^{142,143}$ Pyridostigmine has not been shown to be effective in treatment of constipation associated with slow transit. ${ }^{135}$ Prucalopride, a serotonin receptor agonist, has been shown to alleviate constipations in patients with systemic sclerosis. ${ }^{68}$ Surgical intervention has shown improvement in highly selected patients with refractory constipation but is a last resort. ${ }^{144}$ As systemic sclerosis often affects several regions of the GI tract, patients may be predisposed to increased risk following surgery, including refractory diarrhea and stasis of the ileal arm of an anastamosis. ${ }^{145,146}$

Fecal incontinence is associated with long-standing systemic sclerosis and is characterized by reduced resting pressure and atrophy of the internal anal sphincter. ${ }^{147} \mathrm{Up}$ to $40 \%$ of patients with systemic sclerosis will develop fecal incontinence. ${ }^{148}$ This is often treated with antidiarrheal agents with limited success. Biofeedback and pelvic physical therapy have been shown to alleviate symptoms and quality of life in patients with incontinence. ${ }^{149,150}$ Injectable bulking agents, such as polyacrylamide gel, have been shown to alleviate fecal incontinence scores. ${ }^{151}$ Sacral nerve stimulation has been used for refractory incontinence, resulting in a significant improvement in symptoms. ${ }^{152}$

\section{Malnutrition}

Refractory gastroparesis, SIBO, and pseudo-obstruction are associated with weight loss and malnutrition. Up to $18 \%$ of patients with scleroderma were found to be at high risk of malnutrition in a cross-sectional analysis. ${ }^{153}$ Severe GI disease, as defined by malnutrition, pseudo-obstruction, and/or dependence of supplemental nutrition, was reported in approximately $8 \%$ of patients with scleroderma. ${ }^{8}$ Patients with systemic sclerosis should be routinely screened for malnutrition, as malnutrition correlated with the number of GI complaints, shorter disease duration, oral aperture, and disease severity. ${ }^{154}$ Of the GI complaints, poor appetite best correlated with malnutrition.

Malnutrition has also been shown to correlate with patients' food preferences. ${ }^{155}$ Patients with malnutrition were more likely to avoid dietary fiber, including fruits and vegetables. Consultation with a dietitian is recommended to optimize nutrition.

If patients cannot maintain a normal body mass index by oral intake, enteral nutrition through a jejunostomy tube or parenteral nutrition may be required. Enteral nutrition may additionally be limited by small bowel and colonic dysmotility. Previous studies have shown that patients who require parenteral nutrition find that it is well tolerated and can alleviate malnutrition ${ }^{156}$ (Table).

\section{CONCLUSIONS}

The GI tract is often involved in systemic sclerosis and is associated with significant morbidity. Our current therapy is directed at symptomatic management of these complications. As symptoms do not clearly correlate with affected region(s) of GI dysmotility, objective studies are important in refractory cases to better target therapy. Further work is needed to better understand the pathophysiology, management, and prevention of GI dysmotility in scleroderma.

\section{REFERENCES}

1. Omair MA, Lee P. Effect of gastrointestinal manifestations on quality of life in 87 consecutive patients with systemic sclerosis. J Rheumatol. 2012; 39:992-996. 
2. Thoua NM, Bunce C, Brough G, et al. Assessment of gastrointestinal symptoms in patients with systemic sclerosis in a UK tertiary referral centre. Rheumatology (Oxford). 2010;49:1770-1775

3. Akesson A, Wollheim FA. Organ manifestations in 100 patients with progressive systemic sclerosis: a comparison between the CREST syndrome and diffuse scleroderma. Br J Rheumatol. 1989;28:281-286.

4. Al-Dhaher FF, Pope JE, Ouimet JM. Determinants of morbidity and mortality of systemic sclerosis in Canada. Semin Arthritis Rheum. 2010; 39:269-277.

5. Ruangjutipopan S, Kasitanon N, Louthrenoo W, et al. Causes of death and poor survival prognostic factors in Thai patients with systemic sclerosis. J Med Assoc Thai. 2002;85:1204-1209.

6. Mayes MD, Lacey JV Jr, Beebe-Dimmer J, et al. Prevalence, incidence, survival, and disease characteristics of systemic sclerosis in a large US population. Arthritis Rheum. 2003;48:2246-2255.

7. Nietert PJ, Mitchell HC, Bolster MB, et al. Correlates of depression, including overall and gastrointestinal functional status, among patients with systemic sclerosis. J Rheumatol. 2005;32:51-57.

8. Steen VD, Medsger TA Jr. Severe organ involvement in systemic sclerosis with diffuse scleroderma. Arthritis Rheum. 2000;43:2437-2444.

9. Codullo V, Cereda E, Klersy C, et al. Serum prealbumin is an independent predictor of mortality in systemic sclerosis outpatients. Rheumatology (Oxford). 2016;55:315-319.

10. Hong BY, Giang R, Mbuagbaw L, et al. Factors associated with development of gastrointestinal problems in patients with scleroderma: a systematic review. Syst Rev. 2015;4:188.

11. Fertig N, Domsic RT, Rodriguez-Reyna T, et al. Anti-U11/U12 RNP antibodies in systemic sclerosis: a new serologic marker associated with pulmonary fibrosis. Arthritis Rheum. 2009;61:958-965.

12. Steen V, Domsic RT, Lucas M, et al. A clinical and serologic comparison of African American and Caucasian patients with systemic sclerosis. Arthritis Rheum. 2012;64:2986-2994.

13. Kawaguchi Y, Nakamura Y, Matsumoto I, et al. Muscarinic-3 acetylcholine receptor autoantibody in patients with systemic sclerosis: contribution to severe gastrointestinal tract dysmotility. Ann Rheum Dis 2009;68:710-714.

14. Campbell PM, LeRoy EC. Pathogenesis of systemic sclerosis: a vascular hypothesis. Semin Arthritis Rheum. 1975;4:351-368

15. Stevens MB, Hookman P, Siegel CI, et al. Aperistalsis of the esophagus in patients with connective-tissue disorders and Raynaud's phenomenon N Engl J Med. 1964;270:1218-1222.

16. Steen VD, Medsger TA Jr. The value of the Health Assessment Questionnaire and special patient-generated scales to demonstrate change in systemic sclerosis patients over time. Arthritis Rheum. 1997;40: 1984-1991.

17. Atkinson M, Summerling MD. Oesophageal changes in systemic sclerosis. Gut. 1966;7:402-408.

18. Saladin TA, French AB, Zarafonetis CJ, et al. Esophageal motor abnormalities in scleroderma and related diseases. Am J Dig Dis. 1966;11: $522-535$.

19. Treacy WL, Baggenstoss AH, Slocumb CH, et al. Scleroderma of the esophagus. A correlation of histologic and physiologic findings. Ann Intern Med. 1963;59:351-356.

20. Taroni JN, Martyanov V, Huang CC, et al. Molecular characterization of systemic sclerosis esophageal pathology identifies inflammatory and proliferative signatures. Arthritis Res Ther. 2015;17:194

21. D'Angelo WA, Fries JF, Masi AT, et al. Pathologic observations in systemic sclerosis (scleroderma). A study of fifty-eight autopsy cases and fifty-eight matched controls. Am J Med. 1969;46:428-440.

22. Roberts CG, Hummers LK, Ravich WJ, et al. A case-control study of the pathology of oesophageal disease in systemic sclerosis (scleroderma) Gut. 2006;55:1697-1703.
23. Ebert EC. Esophageal disease in scleroderma. J Clin Gastroenterol. 2006; 40:769-775.

24. Thoua NM, Abdel-Halim M, Forbes A, et al. Fecal incontinence in systemic sclerosis is secondary to neuropathy. Am J Gastroenterol. 2012; 107:597-603

25. Howe S, Eaker EY, Sallustio JE, et al. Antimyenteric neuronal antibodies in scleroderma. J Clin Invest. 1994;94:761-770.

26. Eaker EY, Kuldau JG, Verne GN, et al. Myenteric neuronal antibodies in scleroderma: passive transfer evokes alterations in intestinal myoelectric activity in a rat model. J Lab Clin Med. 1999;133:551-556.

27. Singh J, Mehendiratta V, Del Galdo F, et al. Immunoglobulins from scleroderma patients inhibit the muscarinic receptor activation in internal anal sphincter smooth muscle cells. Am J Physiol Gastrointest Liver Physiol. 2009;297:G1206-G1213.

28. Goldblatt F, Gordon TP, Waterman SA. Antibody-mediated gastrointestinal dysmotility in scleroderma. Gastroenterology. 2002;123: 1144-1150.

29. Singh J, Cohen S, Mehendiratta V, et al. Effects of scleroderma antibodies and pooled human immunoglobulin on anal sphincter and colonic smooth muscle function. Gastroenterology. 2012;143:1308-1318

30. Sohn UD, Harnett KM, De Petris G, et al. Distinct muscarinic receptors, G proteins and phospholipases in esophageal and lower esophageal sphincter circular muscle. J Pharmacol Exp Ther. 1993;267:1205-1214.

31. Cirillo C, Vanden Berghe P, Tack J. Role of serotonin in gastrointestinal physiology and pathology. Minerva Endocrinol. 2011;36:311-324.

32. Jaovisidha K, Csuka ME, Almagro UA, et al. Severe gastrointestinal involvement in systemic sclerosis: report of five cases and review of the literature. Semin Arthritis Rheum. 2005;34:689-702.

33. Nagy G, Kovács J, Zeher M, et al. Analysis of the oral manifestations of systemic sclerosis. Oral Surg Oral Med Oral Pathol. 1994;77:141-146.

34. Pizzo G, Scardina GA, Messina P. Effects of a nonsurgical exercise program on the decreased mouth opening in patients with systemic scleroderma. Clin Oral Investig. 2003;7:175-178.

35. Naylor WP, Douglass CW, Mix E. The nonsurgical treatment of microstomia in scleroderma: a pilot study. Oral Surg Oral Med Oral Pathol. 1984;57:508-511.

36. Bennani I, Lopez R, Bonnet D, et al. Improvement of microstomia in scleroderma after carbon dioxide laser treatment. Case Rep Dermatol. 2016;8:142-150.

37. Baron M, Hudson M, Tatibouet S, et al. The Canadian systemic sclerosis oral health study: orofacial manifestations and oral health-related quality of life in systemic sclerosis compared with the general population. Rheumatology (Oxford). 2014;53:1386-1394

38. Wood RE, Lee P. Analysis of the oral manifestations of systemic sclerosis (scleroderma). Oral Surg Oral Med Oral Pathol. 1988;65:172-178.

39. Montesi A, Pesaresi A, Cavalli ML, et al. Oropharyngeal and esophageal function in scleroderma. Dysphagia. 1991;6:219-223.

40. Turner R, Lipshutz W, Miller W, et al. Esophageal dysfunction in collagen disease. Am J Med Sci. 1973;265:191-199.

41. Thonhofer R, Siegel C, Trummer M, et al. Early endoscopy in systemic sclerosis without gastrointestinal symptoms. Rheumatol Int. 2012;32: $165-168$

42. Kirby DF, Chatterjee S. Evaluation and management of gastrointestinal manifestations in scleroderma. Curr Opin Rheumatol. 2014;26:621-629.

43. Wipff J, Allanore Y, Soussi F, et al. Prevalence of Barrett's esophagus in systemic sclerosis. Arthritis Rheum. 2005;52:2882-2888.

44. Savarino E, Bazzica M, Zentilin P, et al. Gastroesophageal reflux and pulmonary fibrosis in scleroderma: a study using $\mathrm{pH}$-impedance monitoring. Am J Respir Crit Care Med. 2009;179:408-413. 
45. Johnson DA, Drane WE, Curran J, et al. Pulmonary disease in progressive systemic sclerosis. A complication of gastroesop hageal reflux and occult aspiration? Arch Intern Med. 1989;149: 589-593.

46. Zhang XJ, Bonner A, Hudson M, et al. Canadian Scleroderma Research Group, Baron M, Pope J. Association of gastroesophageal factors and worsening of forced vital capacity in systemic sclerosis. J Rheumatol. $2013 ; 40: 850-858$

47. Christmann RB, Wells AU, Capelozzi VL, et al. Gastroesophageal reflux incites interstitial lung disease in systemic sclerosis: clinical, radiologic, histopathologic, and treatment evidence. Semin Arthritis Rheum. 2010;40 241-249.

48. Campbell WL, Schultz JC. Specificity and sensitivity of esophagea motor abnormality in systemic sclerosis (scleroderma) and related diseases: a cineradiographic study. Gastrointest Radiol. 1986;11: 218-222.

49. Lahcene M, Oumnia N, Matougui N, et al. Esophageal dysmotility in scleroderma: a prospective study of 183 cases. Gastroenterol Clin Biol. 2009;33:466-469.

50. Katz PO, Gerson LB, Vela MF. Guidelines for the diagnosis and management of gastroesophageal reflux disease. Am J Gastroenterol. $2013 ; 108: 308$

51. Pakozdi A, Wilson H, Black CM, et al. Does long term therapy with lansoprazole slow progression of oesophageal involvement in systemic sclerosis? Clin Exp Rheumatol. 2009;27(3 suppl 54):5-8.

52. Hendel L, Hage E, Hendel J, et al. Omeprazole in the long-term treatment of severe gastro-oesophageal reflux disease in patients with systemic sclerosis. Aliment Pharmacol Ther. 1992;6:565-577.

53. Stolte M, Meining A, Seifert E, et al. Treatment with lansoprazole also induces hypertrophy of the parietal cells of the stomach. Pathol Res Pract. 2000;196:9-13.

54. Gomm W, von Holt K, Thome F, et al. Association of proton pump inhibitors with risk of dementia: a pharmacoepidemiological claims data analysis. JAMA Neurol. 2016;73:410-416.

55. Lazarus B, Chen Y, Wilson FP, et al. Proton pump inhibitor use and the risk of chronic kidney disease. JAMA Intern Med. 2016;176: 238-246.

56. Zhou B, Huang Y, Li H, et al. Proton-pump inhibitors and risk of fractures an update meta-analysis. Osteoporos Int. 2016;27:339-347.

57. Lambert AA, Lam JO, Paik JJ, et al. Risk of community-acquired pneumonia with outpatient proton-pump inhibitor therapy: a systematic review and meta-analysis. PLoS One. 2015;10:e0128004.

58. Orlando RC, Liu S, Illueca M. Relationship between esomeprazole dose and timing to heartburn resolution in selected patients with gastroesophageal reflux disease. Clin Exp Gastroenterol. 2010;3: $117-125$

59. Hatlebakk JG, Katz PO, Kuo B, et al. Nocturnal gastric acidity and acid breakthrough on different regimens of omeprazole $40 \mathrm{mg}$ daily. Aliment Pharmacol Ther. 1998;12:1235-1240.

60. Xue S, Katz PO, Banerjee $\mathrm{P}$, et al. Bedtime $\mathrm{H}_{2}$ blockers improve nocturnal gastric acid control in GERD patients on proton pump inhibitors. Aliment Pharmacol Ther. 2001;15:1351-1356.

61. Fackler WK, Ours TM, Vaezi MF, et al. Long-term effect of H2RA therapy on nocturnal gastric acid breakthrough. Gastroenterology. 2002; 122:625-632

62. Hendel L, Aggestrup S, Stentoft P. Long-term ranitidine in progressive systemic sclerosis (scleroderma) with gastroesophageal reflux. Scand J Gastroenterol. 1986;21:799-805.

63. Mercado U, Arroyo de Anda R, Avendano L, et al. Metoclopramide response in patients with early diffuse systemic sclerosis. Effects on esophageal motility abnormalities. Clin Exp Rheumatol. 2005;23: 685-688.
64. Johnson DA, Drane WE, Curran J, et al. Metoclopramide response in patients with progressive systemic sclerosis. Effect on esophageal and gastric motility abnormalities. Arch Intern Med. 1987;147:1597-1601.

65. Ramirez-Mata M, Ibanez G, Alarcon-Segovia D. Stimulatory effect of metoclopramide on the esophagus and lower esophageal sphincter of patients of patients with PSS. Arthritis Rheum. 1977;20:30-34.

66. Foocharoen C, Chunlertrih K, Mairiang P, et al. Effectiveness of add-on therapy with domperidone vs alginic acid in PPI partial response GERD in systemic sclerosis. Rheumatology (Oxford). 2016;56:214-222.

67. Quinn N, Parkes D, Jackson G, et al. Cardiotoxicity of domperidone. Lancet. 1985;2:724.

68. Boeckxstaens GE, Bartelsman JF, Lauwers L, et al. Treatment of GI dysmotility in scleroderma with the new enterokinetic agent prucalopride Am J Gastroenterol. 2002;97:194-197.

69. Kent MS, Luketich JD, Irshad K, et al. Comparison of surgical approaches to recalcitrant gastroesophageal reflux disease in the patient with scleroderma. Ann Thorac Surg. 2007;84:1710-1716.

70. Karamanolis GP, Panopoulos S, Karlaftis A, et al. Beneficial effect of the $5-\mathrm{HT}_{1 \mathrm{~A}}$ receptor agonist buspirone on esophageal dysfunction associated with systemic sclerosis: a pilot study. United European Gastroenterol J. 2015;3:266-271

71. Karamanolis GP, Panopoulos S, Denaxas K, et al. The $5-\mathrm{HT}_{1 \mathrm{~A}}$ receptor agonist buspirone improves esophageal motor function and symptoms in systemic sclerosis: a 4-week, open-label trial. Arthritis Res Ther. 2016; $18: 195$.

72. Curcic J, Schwizer A, Kaufman E, et al. Effects of baclofen on the functional anatomy of the oesophago-gastric junction and proximal stomach in healthy volunteers and patients with GERD assessed by magnetic resonance imaging and high-resolution manometry: a randomized controlled double-blind study. Aliment Pharmacol Ther. 2014;40:1230-1240.

73. Camilleri M, Parkman HP, Shafi MA, et al. Clinical guideline: management of gastroparesis. Am J Gastroenterol. 2013;108:18.

74. Rao SS, Camilleri M, Hasler WL, et al. Evaluation of gastrointestinal transit in clinical practice: position paper of the American and European Neurogastroenterology and Motility Societies. Neurogastroenterol Motil. 2011;23:8-23.

75. Ziessman HA, Chander A, Clarke JO, et al. The added diagnostic value of liquid gastric emptying compared with solid emptying alone. J Nucl Med. 2009;50:726-731

76. Cozzi F, Parisi G, Ciprian L, et al. Gastric dysmotility after liquid bolus ingestion in systemic sclerosis: an ultrasonographic study. Rheumatol Int 2012;32:1219-1223.

77. Sachdeva P, Malhotra N, Pathikonda M, et al. Gastric emptying of solids and liquids for evaluation for gastroparesis. Dig Dis Sci. 2011;56: 1138-1146.

78. Kuo B, McCallum RW, Koch KL, et al. Comparison of gastric emptying of a nondigestible capsule to a radio-labelled meal in healthy and gastroparetic subjects. Aliment Pharmacol Ther. 2008;27:186-196.

79. Ghoos YF, Maes BD, Geypens BJ, et al. Measurement of gastric emptying rate of solids by means of a carbon-labeled octanoic acid breath test. Gastroenterology. 1993;104:1640-1647.

80. Szarka LA, Camilleri M, Vella A, et al. A stable isotope breath test with a standard meal for abnormal gastric emptying of solids in the clinic and in research. Clin Gastroenterol Hepatol. 2008;6:635.

81. Jehangir W, Mohamed SR, Sadda A, et al. Morphine-induced gastroparesis. Am J Med Sci. 2015;350:e3.

82. Pautola L, Hakala T. Medication-induced acute esophageal necrosis: a case report. J Med Case Rep. 2016;10:267.

83. Snape WJ Jr, Battle WM, Schwartz SS, et al. Metoclopramide to treat gastroparesis due to diabetes mellitus: a double-blind, controlled trial Ann Intern Med. 1982;96:444-446. 
84. Ricci DA, Saltzman MB, Meyer C, et al. Effect of metoclopramide in diabetic gastroparesis. J Clin Gastroenterol. 1985;7:25-32.

85. McCallum RW, Ricci DA, Rakatansky H, et al. A multicenter placebo-controlled clinical trial of oral metoclopramide in diabetic gastroparesis. Diabetes Care. 1983;6:463-467.

86. Sridhar KR, Lange RC, Magyar L, et al. Prevalence of impaired gastric emptying of solids in systemic sclerosis: diagnostic and therapeutic implications. J Lab Clin Med. 1998;132:541-546.

87. Karamanolis G, Tack J. Promotility medications - now and in the future. Dig Dis. 2006;24:297-307.

88. FDA Press Announcement. FDA requires boxed warning and risk mitigation strategy for metoclopramide-containing drugs [press release]. 2017. Available at: http://www.fda.gov/NewsEvents/Newsroom/ PressAnnouncements/ucm149533.htm. Accessed February 1, 2017.

89. Ganzini L, Casey DE, Hoffman WF, et al. The prevalence of metoclopramide-induced tardive dyskinesia and acute extrapyramidal movement disorders. Arch Intern Med. 1993;153:1469-1475.

90. Tung A, Sweitzer B, Cutter T. Cardiac arrest after labetalol and metoclopramide administration in a patient with scleroderma. Anesth Analg. 2002;95:1667.

91. Patterson D, Abell T, Rothstein R, et al. A double-blind multicenter comparison of domperidone and metoclopramide in the treatment of diabetic patients with symptoms of gastroparesis. Am J Gastroenterol. 1999;94:1230-1234.

92. Soykan I, Sarosiek I, McCallum RW. The effect of chronic oral domperidone therapy on gastrointestinal symptoms, gastric emptying, and quality of life in patients with gastroparesis. Am J Gastroenterol. 1997;92: 976-980.

93. Horowitz M, Harding PE, Chatterton BE, et al. Acute and chronic effects of domperidone on gastric emptying in diabetic autonomic neuropathy. Dig Dis Sci. 1985;30:1-9.

94. Davis RH, Clench MH, Mathias JR. Effects of domperidone in patients with chronic unexplained upper gastrointestinal symptoms: a double-blind, placebo-controlled study. Dig Dis Sci. 1988;33:1505-1511.

95. Janssens J, Peeters TL, Vantrappen G, et al. Improvement of gastric emptying in diabetic gastroparesis by erythromycin. Preliminary studies. N Engl J Med. 1990;322:1028-1031.

96. Fiorucci S, Distrutti E, Bassotti G, et al. Effect of erythromycin administration on upper gastrointestinal motility in scleroderma patients. Scand J Gastroenterol. 1994;29:807-813.

97. Leung WK, Chan FK, Fung SS, et al. Effect of oral erythromycin on gastric and small bowel transit time of capsule endoscopy. World $J$ Gastroenterol. 2005;11:4865-4868.

98. Verne GN, Eaker EY, Hardy E, et al. Effect of octreotide and erythromycin on idiopathic and scleroderma-associated intestinal pseudoobstruction. Dig Dis Sci. 1995;40:1892-1901.

99. Arts J, Caenepeel P, Verbeke K, et al. Influence of erythromycin on gastric emptying and meal related symptoms in functional dyspepsia with delayed gastric emptying. Gut. 2005;54:455-460.

100. Edelbroek MA, Horowitz M, Wishart JM, et al. Effects of erythromycin on gastric emptying, alcohol absorption and small intestinal transit in normal subjects. $J$ Nucl Med. 1993;34:582-588.

101. Koulaouzidis A, Giannakou A, Yung DE, et al. Do prokinetics influence the completion rate in small-bowel capsule endoscopy? A systematic review and meta-analysis. Curr Med Res Opin. 2013;29:1171-1185.

102. Deane AM, Wong GL, Horowitz M, et al. Randomized double-blind crossover study to determine the effects of erythromycin on small intestinal nutrient absorption and transit in the critically ill. Am J Clin Nutr. 2012;95:1396-1402

103. Folwaczny C, Läritz M, Meurer M, et al. Effects of various prokinetic drugs on gastrointestinal transit times in patients with progressive systemic scleroderma. Z Gastroenterol. 1997;35:905-912.
104. Braden B, Enghofer M, Schaub M, et al. Long-term cisapride treatment improves diabetic gastroparesis but not glycaemic control. Aliment Pharmacol Ther. 2002;16:1341-1346.

105. McHugh S, Lico S, Diamant NE. Cisapride vs metoclopramide. An acute study in diabetic gastroparesis. Dig Dis Sci. 1992;37:997-1001.

106. Madsen JL. Effects of cisapride on gastrointestinal transit in healthy humans. Dig Dis Sci. 1990;35:1500-1504.

107. Hennessy S, Leonard CE, Newcomb C, et al. Cisapride and ventricular arrhythmia. Br J Clin Pharmacol. 2008;66:375-385.

108. Tack J, Janssen P, Masaoka T, et al. Efficacy of buspirone, a fundus-relaxing drug, in patients with functional dyspepsia. Clin Gastroenterol Hepatol. 2012;10:1239-1245.

109. Mansi C, Borro P, Giacomini M, et al. Comparative effects of levosulpiride and cisapride on gastric emptying and symptoms in patient with functional dyspepsia and gastroparesis. Aliment Pharmacol Ther 2000;14:561-569.

110. Mearin F, Rodrigo L, Pérez-Mota A, et al. Levosulpiride and cisapride in the treatment of dysmotility-like functional dyspepsia: a randomized, double-masked trial. Clin Gastroenterol Hepatol. 2004;2:301-308.

111. Corazza GR, Biagi F, Albano O, et al. Levosulpiride in functional dyspepsia: a multicentric, double-blind, controlled trial. Ital J Gastroenterol. 1996;28:317-323.

112. Murray CD, Martin NM, Patterson M, et al. Ghrelin enhances gastric emptying in diabetic gastroparesis: a double blind, placebo controlled crossover study. Gut. 2005;54:1693-1698.

113. Tack J, Depoortere I, Bisschops R, et al. Influence of ghrelin on gastric emptying and meal-related symptoms in idiopathic gastroparesis. Aliment Pharmacol Ther. 2005;22:847-853.

114. Ariyasu H, Iwakura H, Yukawa N, et al. Clinical effects of ghrelin on gastrointestinal involvement in patients with systemic sclerosis. Endocr J. 2014;61:735-742

115. Marie I, Ducrotte P, Denis P, et al. Outcome of small-bowel motor impairment in systemic sclerosis - a prospective manometric 5-yr follow-up. Rheumatology (Oxford). 2007;46:150-153.

116. Savarino E, Mei F, Parodi A, et al. Gastrointestinal motility disorde assessment in systemic sclerosis. Rheumatology (Oxford). 2013;52: 1095-1100.

117. Fynne L, Worsøe J, Gregersen T, et al. Gastrointestinal transit in patients with systemic sclerosis. Scand J Gastroenterol. 2011;46:1187-1193.

118. Roland BC, Ciarleglio MM, Clarke JO, et al. Small intestinal transit time is delayed in small intestinal bacterial overgrowth. J Clin Gastroenterol. 2015;49:571-576.

119. Miazga A, Osiński M, Cichy W, et al. Current views on the etiopathogenesis, clinical manifestation, diagnostics, treatment and correlation with other nosological entities of SIBO. Adv Med Sci. 2015;60: $118-124$

120. Bures J, Cyrany J, Kohoutova D, et al. Small intestinal bacterial overgrowth syndrome. World J Gastroenterol. 2010;16:2978-2990.

121. Marie I, Ducrotté P, Denis P, et al. Small intestinal bacterial overgrowth in systemic sclerosis. Rheumatology (Oxford). 2009;48:1314-1319.

122. Drossman DA, Chey WD, Johanson JF, et al. Clinical trial: lubiprostone in patients with constipation-associated irritable bowel syndrome - results of two randomized, placebo-controlled studies. Aliment Pharmacol Ther. $2009 \cdot 29 \cdot 329-341$

123. Simrén M, Stotzer PO. Use and abuse of hydrogen breath tests. Gut. 2006 55:297-303.

124. Valdovinos MA, Camilleri M, Thomforde GM, et al. Reduced accuracy of ${ }^{14} \mathrm{C}$-D-xylose breath test for detecting bacterial overgrowth in gastrointestinal motility disorders. Scand J Gastroenterol. 1993;28: 963-968. 
125. Lewis SJ, Franco S, Young G, et al. Altered bowel function and duodenal bacterial overgrowth in patients treated with omeprazole. Aliment Pharmacol Ther. 1996;10:557-561.

126. Di Stefano M, Malservisi S, Veneto $G$, et al. Rifaximin versus chlortetracycline in the short-term treatment of small intestinal bacterial overgrowth. Aliment Pharmacol Ther. 2000;14:551-556.

127. Attar A, Flourié B, Rambaud JC, et al. Antibiotic efficacy in small intestinal bacterial overgrowth-related chronic diarrhea: a crossover, randomized trial. Gastroenterology. 1999;117:794-797.

128. Lauritano EC, Gabrielli M, Scarpellini E, et al. Antibiotic therapy in small intestinal bacterial overgrowth: rifaximin versus metronidazole. Eur Rev Med Pharmacol Sci. 2009;13:111-116.

129. Barrett JS, Canale KE, Gearry RB, et al. Probiotic effects on intestinal fermentation patterns in patients with irritable bowel syndrome. World $J$ Gastroenterol. 2008;14:5020-5024.

130. Soifer LO, Peralta D, Dima G, et al. Comparative clinical efficacy of a probiotic vs. an antibiotic in the treatment of patients with intestinal bacterial overgrowth and chronic abdominal functional distension: a pilot study. Acta Gastroenterol Latinoam. 2010;40:323-327.

131. Frech TM, Khanna D, Maranian P, et al. Probiotics for the treatment of systemic sclerosis-associated gastrointestinal bloating/ distention. Clin Exp Rheumatol. 2011;29(2 suppl 65):S22-S25

132. Soudah HC, Hasler WL, Owyang C. Effect of octreotide on intestinal motility and bacterial overgrowth in scleroderma. N Engl J Med. 1991; 325:1461-1467.

133. Rees WD, Leigh RJ, Christofides ND, et al. Interdigestive motor activity in patients with systemic sclerosis. Gastroenterology. 1982; $83: 575-580$.

134. Camilleri M, Malagelada JR, Abell TL, et al. Effect of six weeks of treatment with cisapride in gastroparesis and intestinal pseudoobstruction. Gastroenterology. 1989;96:704-712.

135. O'Dea CJ, Brookes JH, Wattchow DA. The efficacy of treatment of patients with severe constipation or recurrent pseudo-obstruction with pyridostigmine. Colorectal Dis. 2010;12:540-548.

136. Nikou GC, Toumpanakis C, Katsiari C, et al. Treatment of small intestinal disease in systemic sclerosis with octreotide: a prospective study in seven patients. J Clin Rheumatol. 2007;13:119-123.

137. Balbir-Gurman A, Brook OR, Chermesh I, et al. Pneumatosis cystoides intestinalis in scleroderma-related conditions. Intern Med J. 2012;42:323-329.

138. Malcolm A, Ellard K. Intestinal perforation associated with octreotide therapy in scleroderma. Am J Gastroenterol. 2001;96:3206-3208.

139. Franck-Larsson K, Graf W, Rönnblom A. Lower gastrointestinal symptoms and quality of life in patients with systemic sclerosis: a population-based study. Eur J Gastroenterol Hepatol. 2009;21:176-182.

140. Ormeci AC, Akyuz F, Baran B, et al. Retention during capsule endoscopy: is it a real problem in routine practice? J Int Med Res. 2016;44:968-975.

141. Awad RA, Camacho S. A randomized, double-blind, placebo-controlled trial of polyethylene glycol effects on fasting and postprandial rectal sensitivity and symptoms in hypersensitive constipation-predominant irritable bowel syndrome. Colorectal Dis. 2010;12:1131-1138.

142. Gasbarrini A, Corazza GR, Gasbarrini G, et al. Methodology and indications of $\mathrm{H}_{2}$-breath testing in gastrointestinal diseases: the Rome Consensus Conference. Aliment Pharmacol Ther. 2009; 29(Suppl 1):1-49.

143. Rothstein RD, Friedenberg FK. Linaclotide: a novel compound for the treatment of irritable bowel syndrome with constipation. Expert Opin Pharmacother. 2013;14:2125-2132.

144. Lindsey I, Farmer CR, Cunningham IG. Subtotal colectomy and cecosigmoid anastomosis for colonic systemic sclerosis: report of a case and review of the literature. Dis Colon Rectum. 2003;46: 1706-1711.

145. Marchesi F, Rapacchi C, Cecchini S, et al. Late surgical complications of subtotal colectomy with antiperistaltic caeco-rectal anastomosis for slow transit constipation. A critical analysis. Ann Ital Chir. 2016;87: 31-35.

146. Dudekula A, Huftless S, Bielefeldt K. Colectomy for constipation: time trends and impact based on the US Nationwide Inpatient Sample, 1998-2011. Aliment Pharmacol Ther. 2015;42:1281-1293.

147. Thoua NM, Schizas A, Forbes A, et al. Internal anal sphincter atrophy in patients with systemic sclerosis. Rheumatology (Oxford). 2011;50: 1596-1602.

148. Trezza M, Krogh K, Egekvist H, et al. Bowel problems in patients with systemic sclerosis. Scand J Gastroenterol. 1999;34:409-413.

149. Collins J, Mazor Y, Jones M, et al. Efficacy of anorectal biofeedback in scleroderma patients with fecal incontinence: a case-control study. Scand J Gastroenterol. 2016;51:1433-1438.

150. Norton C, Cody JD. Biofeedback and/or sphincter exercises for the treatment of faecal incontinence in adults. Cochrane Database Syst Rev. 2012;11:CD002111.

151. Altman D, Hjern F, Zetterström J. Transanal submucosal polyacrylamide gel injection treatment of anal incontinence: a randomized controlled trial. Acta Obstet Gynecol Scand. 2016;95:528-533.

152. Kenefick NJ, Vaizey CJ, Nicholls RJ, et al. Sacral nerve stimulation for faecal incontinence due to systemic sclerosis. Gut. 2002;51: $881-883$.

153. Baron M, Hudson M, Steele R, et al. Malnutrition is common in systemic sclerosis: results from the Canadian scleroderma research group database. J Rheumatol. 2009;36:2737-2743.

154. Baron M, Bernier P, Cote LF, et al. Screening and therapy for malnutrition and related gastrointestinal disorders in systemic sclerosis: recommendations of a North American expert panel. Clin Exp Rheumatol. 2010;28(2 suppl 58):S42-S46.

155. Lundberg AC, Akesson A, Akesson B. Dietary intake and nutritional status in patients with systemic sclerosis. Ann Rheum Dis. 1992;51: 1143-1148.

156. Brown M, Teubner A, Shaffer J, et al. Home parenteral nutrition - an effective and safe long-term therapy for systemic sclerosis-related intestinal failure. Rheumatology (Oxford). 2008;47:176-179. 